\title{
COLORADOSCHOOLOFMINES
}

EARTH•ENERGY•ENVIRONMENT

DiVISION OF ECONOMICS AND BUSINESS

WORKING PAPER SERIES

\section{A Shared Sense of Responsibility: \\ Money versus effort contributions in the voluntary provision of public goods}

Jared C. Carbone

Robert S. Gazzale

\author{
Working Paper 2014-06 \\ http://econbus . mines .edu/working-papers/wp201406.pdf \\ Colorado School of Mines \\ Division of Economics and Business \\ 1500 Illinois Street \\ Golden, CO 80401
}

September 2014

(c) 2014 by the listed authors. All rights reserved. 
Colorado School of Mines

Division of Economics and Business

Working Paper No. 2014-06

September 2014

Title:

A Shared Sense of Responsibility:

Money versus effort contributions in the voluntary provision of public goods*

Author(s):

Jared C. Carbone

Division of Economics and Business

Colorado School of Mines

Golden, CO 80401-1887

jcarbone@mines.edu

Robert S. Gazzale

Department of Economics

University of Toronto

robert.gazzale@utoronto.ca

\begin{abstract}
A frequently cited argument against the use of market-based instruments to provide public goods is that they diminish our sense of responsibility to be good citizens. In this paper, we report on the results of a laboratory experiment designed to explore the idea that this distrust stems from the ability of some members of society to contribute to the public good with money instead of time or effort even when the level of total contributions is held constant. In our experiments, subjects complete lab tasks as a contribution to a public good - carbon emission reductions. We look at how the number of lab tasks completed by subjects changes when their peers take advantage of an offer to buy out, i.e., contribute money in lieu of effort. We find that on average subjects reduce the number of completed tasks when their peers buy out. However, the aggregate result masks significant heterogeneity across individual responses. Those who choose not to buy out despite its expected profitability have no response to the treatment while those for whom it would not be profitable to buy out register large reductions in effort contributions. The magnitude of these responses is increasing in the share of the group that accepts the buyout offer, suggesting that it is the act of peers buying out rather than the simple introduction of monetary incentives that is the source of the effect.
\end{abstract}

JEL classifications: C90, C91, H41, Q54

Keywords: experimental economics; public goods; effort contributions; environment; climate change.

\footnotetext{
${ }^{*}$ We gratefully acknowledge support from the Norwegian Research Council as part of the NORKLIMA project. The views expressed here and any errors are our own.
} 


\title{
A Shared SEnSE Of Responsibility: Money Versus EFFort Contributions in the Voluntary Provision of Public GoOds*
}

JUNE 2014

\begin{abstract}
A frequently cited argument against the use of market-based instruments to provide public goods is that they diminish our sense of responsibility to be good citizens. In this paper, we report on the results of a laboratory experiment designed to explore the idea that this distrust stems from the ability of some members of society to contribute to the public good with money instead of time or effort even when the level of total contributions is held constant. In our experiments, subjects complete lab tasks as a contribution to a public good - carbon emission reductions. We look at how the number of lab tasks completed by subjects changes when their peers take advantage of an offer to buy out, i.e., contribute money in lieu of effort. We find that on average subjects reduce the number of completed tasks when their peers buy out. However, the aggregate result masks significant heterogeneity across individual responses. Those who choose not to buy out despite its expected profitability have no response to the treatment while those for whom it would not be profitable to buy out register large reductions in effort contributions. The magnitude of these responses is increasing in the share of the group that accepts the buyout offer, suggesting that it is the act of peers buying out rather than the simple introduction of monetary incentives that is the source of the effect.
\end{abstract}

JEL Classification: C90, C91, H41, Q54

Key words: experimental economics, public goods, effort contribution, environment, climate change

\section{INTRODUCTION}

A frequently cited argument against the use of market-based instruments to provide public goods is that by diminishing our sense of responsibility to be good citizens, these mechanisms may ultimately reduce voluntary contributions. For example, many environmental interest groups oppose the use of emission permit trading systems (cap-and-trade) to control air pollution despite their cost effectiveness (Heal 2007). Two related but distinct objections to market-based instruments have been noted. First, they argue that by changing pollution from a sin against nature, remedied only by personal atonement, into a commodity that can be bought and sold with no special social consequences, market-based instruments may weaken our resolve in dealing with environmental challenges. A second aspect which may reduce the shared sense of responsibility and sacrifice is the fact that these market-based mechanisms allow some to contribute money in lieu of effort. If some choosing to contribute money instead of effort causes others to reduce their voluntary effort contributions, it presents a challenge for policymakers as the market's efficiency gains arise from those with a high opportunity cost of direct effort choosing monetary contributions instead.

In this paper, we focus on this second objection to market-based instruments. We report on results of laboratory experiment designed to explore the hypothesis that an individual's voluntary

\footnotetext{
${ }^{*}$ We gratefully acknowledge support from the Norwegian Research Council as part of the NORKLIMA project. The views expressed here and any errors are our own.
} 
effort contributions to the public good is affected by the contribution vehicle - personal effort versus money - used by her peers.

This hypothesis has a long history in political philosophy (Rousseau 1762), and has more recently been articulated in the context of environmental policy by Sandel (2012). Circumstantial evidence does suggest that individuals differentiate between money and effort contributions to the public good even when they ultimately result in the same level of overall provision. For example, environmental activist Al Gore was widely criticized in 2007 when a think tank revealed that Gore's personal estate required twenty times as much electricity as a typical household. Gore declared his lifestyle carbon neutral because he purchased offsets to his polluting activities, but many viewed this gesture as insufficient. The president of the think tank was quoted, "If he [Gore] is going to be a spokesman for global warming, he has to be willing to make the same sacrifices [as those unable to afford offsets]" (Humphrey 2007). The clear implication was that Gore would be a more sympathetic advocate for his cause if he "walked the walk" by making lifestyle changes that directly reduced the size of his carbon footprint rather than via financial transaction. ${ }^{1}$

Whether these perceived differences translate into reduced contributions from those who continue to supply effort is an open question. While we are aware of no previous study that tests for a causal effect, previous results lend support to the conjecture. For example, previous experiments have documented conditional cooperation in the provision of public goods, whereby a subject's voluntary contribution to the public good is increasing in the contribution of others (Gächter 2007). If individuals effectively discount monetary contributions relative to equivalent effort contributions, then observing reduced effort contributions when peers contribute money could be interpreted as a form of conditional cooperation. The previous studies do not, however, focus on this distinction between money and effort contributions. In other contexts, experiments have examined the general issue of whether people differentiate between money and equivalent time or effort, finding mixed results (Brüggen and Strobel 2007, Ellingsen and Johannesson 2009, Vilares, Dam and Kording 2011). None of these studies focuses on public goods provision. Finally, there is an extensive literature in economics and psychology focused on measuring the crowding out of intrinsic motivation when explicit rewards (markets or monetary incentives) for performance are introduced (e.g., Gneezy and Rustichini 2000, Frey and Jegen 2001). None of the studies examines how the behavior of peers - specifically their decision to buy their way out of making direct contributions to public goods - affects a person's motivation.

To test whether voluntary effort contributions are affected by the contribution vehicle chosen by peers, the institution we study is a buyout option. In an environment where participation, but not effort, is enforceable, we allow individuals to contribute money in lieu of effort. In our experiment, subjects complete simple lab tasks. In some rounds, task performance is rewarded

\footnotetext{
${ }^{1}$ Similarly, the Mid-Atlantic Regional Council of Carpenters came under fire when it became known that they regularly outsource shifts on their picket lines to homeless people because of the high cost of missing work to the union's own members (Alexander 2007). Food cooperatives frequently require effort contributions from their members. For example, the Park Slope Food Coop (the oldest and largest member-owned food cooperative in the U.S.) requires each household adult to contribute 2.75 hours every four weeks. Its website notes that while "volunteer" effort keeps prices low, "another goal accomplished when members are doing 75\% of the work of the Coop is a feeling of being a memberowner that one cannot get from merely investing one's money."(http://foodcoop.com/go.php?id=40)
} 
with reductions in carbon emissions (a public good), where more tasks completed leads to larger emission reductions. That is, we ask subjects to make effort contributions to the public good. In other rounds, task performance is rewarded with a cash payment, where subjects receive a piece rate per task completed. In treatment sessions, we introduce the possibility of a buyout in later emission-reduction rounds: subjects can pay a fee (used to purchase emission reductions) that relieves them of the responsibility to complete tasks for emission reductions and allows them to continue to work for cash payments. We test for the effect of peer buyouts by comparing the number of tasks completed by treatment-session subjects who do not buy out to the number of tasks completed by subjects in control sessions in which no buyout option was available.

Our hypothesis is that peers choosing to contribute money in lieu of effort leads to a reduction in the effort contributions of those who continue to contribute effort. To test this hypothesis, it is necessary to have a laboratory environment where: i) subjects have the choice whether to buy out; ii) within a group, there are both subjects who do and do not buy out; and iii) the number accepting the buyout varies across groups. To capture the spirit of the efficiency objectives of market-based mechanisms, we also seek a setting where those with the highest opportunity cost of effort find the buyout most attractive. We achieve these goals in our fair-buyout treatment: we offered the buyout to all at a price that replaces the average effort contribution, but will only be affordable to those with the highest outside option earnings.

While our fair-buyout treatment has a number of desirable features, a problem with choice determining who buys out is that those who do not buy out (and thus the group to which we compare control subjects) is not a random sample. If those accepting the buyout would have been those with the highest effort contributions, then a reduction in average effort contributions, relative to the control group, could be explained by composition effects. While we present evidence that the effect identified in this treatment is not due to selection, we also conduct a second treatment where a profitable buyout option is only offered to a random subset of subjects. While this might be less realistic, the comparison between treatment subjects not offered the buyout and control subjects is unaffected by selection. However, subjects reducing effort contributions in this case might be reacting to a perceived unfairness in not being offered a profitable buyout opportunity.

In both treatments, the buyout option reduces the number of emission-reducing tasks completed by subjects who do not buy out (relative to the number of tasks completed by control subjects). However, the aggregate result masks significant heterogeneity across individual responses. Those who do not accept the fair buyout despite its expected profitability have no response to the treatment while those for whom it would not be profitable to buy out register large reductions in task performance. Further, the effect depends on the act of peers buying out as opposed to just the introduction of the buyout option. We find a 5-10\% reduction in emission-reducing tasks completed for every 10 percentage-point increase in subjects who buy out (if the response is assumed to be linear). Our two treatments yield very similar responses, suggesting that neither selection nor the perceived unfairness of random selection are likely to explain our results.

Climate change policy motivates the main ideas in the paper and serves as the context of our experiment. It is easy to imagine their relevance in other contexts however. If our hypothesis is 
correct, then people may experience important effects on their intrinsic motivation in any setting where voluntary service is a mainstay of public goods provision. For example, many of the basic functions of local communities rely intensively on donations of time and effort from their members to community centers, schools and town councils. Our results suggest that market-based initiatives designed to bolster contributions to these activities (or allow them to be made as efficiently as possible) may have hidden costs in the form of reduced voluntary effort contributions. They may also help explain why many groups and organizations expressly prohibit their members from replacing effort obligations with cash contributions.

Section 2 describes the design of the laboratory experiment and Section 3 describes the results as well as robustness checks. Section 4 discusses some of the broader implications of our findings and offers suggestions for future research.

\section{EXPERIMENT DESIGN}

In this section we present our experiment design. We first describe the experiment in detail based on the design of the control sessions where no buyout option is available. We then describe the treatment in which all subjects are offered the option to buy out (fair buyout) and the treatment based on the randomly-assigned buyout (unfair buyout). Finally, we discuss possible confounding effects and specific aspects of the experiment designed to address these issues.

We conducted our sessions with undergraduate students at Williams College. Approximately 16 students participated in each session, without duplication. ${ }^{2}$ A total of 61 subjects participated in the control sessions, with 64 and 61 in the fair and unfair buyout sessions. Subjects earned $\$ 16.50$ on average, which includes a $\$ 5$ show-up fee. Sessions lasted approximately 60-75 minutes. The experiment was programmed and conducted with z-Tree (Fischbacher 2007).

\subsection{Control Session Procedures}

At the start of a session, each of approximately 16 subjects was randomly assigned a computer, implicitly assigning each subject to one of two equally sized groups. Each subject received a written copy of the instructions (included in Appendix A) which were subsequently read aloud. At then end of each session, subjects completed a brief demographic questionnaire.

Each session proceeded in a series of five-minute rounds in which subjects had the opportunity to complete computer-based tasks. In earning rounds, a subject earned a piece rate for each task completed. In environment rounds, we presented subjects with a different task. As a reward for performance in these rounds, we purchased and retired carbon emission permits from the EU Emission Trading Scheme (EU ETS) in proportion to the number of tasks completed. ${ }^{3}$

\footnotetext{
${ }^{2}$ Subjects were recruited through the online recruitment system ORSEE (Greiner 2004).

${ }^{3}$ See http://ec.europa.eu/clima/policies/ets/index_en.htm for information on the EU ETS. That we implement public good contributions by making purchases on a market contains some obvious irony. Importantly, any objection to making pollution control a commodity that can be bought and sold should register in both the control and treatments. The difference between the control and treatments is whether a peer's contribution stems from her effort or her money, and the interaction between the treatment and the background permit market is not obvious. While the presence of the market-based instrument may make buyout behavior more salient, the fact that all contributions
} 
At the beginning of each round, subjects learned whether the round was an environment or an earning round. Subjects knew neither the total number of rounds nor how many of each type of round. In fact, all sessions lasted five rounds and started with an environment round, with rounds alternating between environment and earning. Thus rounds 1, 3 and 5 were environment rounds and rounds 2 and 4 were earning rounds. At the end of each earning round, the subject's screen displayed the number of tasks she completed as well as her earnings in dollars for the round. At the end of each environment round, her screen displayed the number of tasks both she and her group completed as well as the number of tons of carbon emissions both she and her group prevented. At all points in the session, a subject had access to all previously revealed information.

We used two tasks: an encryption task and a counting task. Subjects completed one task in earning rounds and the other in environment rounds, with the assignment of tasks varied between session. For the encryption task, the subject's computer screen displayed a table translating each letter of the alphabet into a unique two-digit number. ${ }^{4}$ For each task, the subject's screen displayed two letters. The subject successfully completed the task by translating the letters into their numeric equivalent and entering the correct four numbers. For each counting task, a subject's computer screen displayed a table with four rows and four columns, with each cell containing a randomly generated " 0 " or " 1 ". The subject successfully completed the task by correctly entering the total number of zeros in the table. For both task types, the subject received the next task only after completing the current task.

The subject received ten cents per completed encryption task in earning rounds and we retired one permit per 150 completed tasks when we presented encryption tasks in environment rounds. The subject received 7.5 cents per completed counting task in earning rounds and we retired one permit per 200 completed tasks when we presented counting tasks in environment rounds. ${ }^{5}$ Prior to the first round, subjects participated in two one-minute practice rounds: one for each of the tasks.

We now highlight some additional aspects of the experiment environment. First, in addition to a window for interacting with the experiment, a subject's computer screen displayed an internet browser. We included the browser to establish an opportunity cost of completing the tasks. Subject instructions noted the existence of the internet browser and made it clear - in neutral language - that they were free to use it during the experiment.

The instructions also included basic information about the link between carbon emissions and global warming, and described how we would purchase permits. They also explained how subjects could verify the permit purchases after the session.

While we informed each subject about the number of environment tasks completed by members of her group, we provided no information about the other group. Likewise, in the treatment sessions we describe next, a subject learns how many group members accepted the buyout, but learns nothing about the other group. We split each session into two fixed groups for two reasons.

eventually involve money could hinder finding a significant treatment effect.

${ }^{4}$ We randomly generated one encryption key each round for all subjects.

${ }^{5}$ Pilot-session subjects completed approximately $25 \%$ fewer encryption tasks per round than counting tasks. 
First, there is evidence that even weak group identity may make the actions of others more salient (e.g., Chen and Li 2009). Thus establishing group membership may make the information we provided about peers' performance and choices more important. Second, a subject did not know which individuals in the room were in her group. It was our hope that this uncertainty would make a neighbor's audible keyboard effort less relevant, reducing the likelihood that a subject conditioned her effort on her neighbor's current actions, as opposed to the buyout option and the number of group members accepting the buyout.

\subsection{Treatment Sessions - Fair Buyout}

Treatment sessions proceeded in the same manner as control sessions with the difference that we surprised subjects with a buyout option at the start of the second and third environment rounds (rounds 3 and 5). The buyout option enabled a subject to pay a buyout fee and complete tasks for earning money - just as in one of the previous earning rounds — in lieu of completing tasks to retire emission permits. The proceeds of the buyout fees were then used to purchase as many carbon permits as possible. The round proceeded as a normal environment round for those subjects not accepting the buyout. ${ }^{6}$

In the fair-buyout treatment, we informed subjects that the buyout option was available to all in the group on the same terms. In specifying the terms of the buyout, we had two goals. First, we wanted emission permits purchased with the buyout fees to approximately replace the contributions those accepting the buyout would have made had they instead performed environment tasks. We accomplished this by setting the buyout fee to exactly offset the average number of permits produced by the group's subjects in the first environment round. Second, we wanted to make sure that some, but not all, subjects accepted the buyout. We accomplished this goal by strategically setting the piece rate on earning tasks for those accepting the buyout. For each group, we calculated the median number of tasks completed in the previous earning round, and set the piece rate so that earnings from this median number of tasks is exactly equaled the buyout fee. While we informed subjects that the buyout fee exactly replaced the group's average round-1 permit production, we only told them the piece rate they would receive upon acceptance of the buyout without indicating how we calculated the rate.

Subjects simultaneously chose whether to accept the buyout option at the beginning of the round. When making this decision, each subject's monitor displayed information about the expected profitability of accepting the buyout option. That is, based on the piece rate established for the round, we calculated the amount of money the subject would earn if she replicated her performance from the previous earning round. We then subtracted the buyout fee from this number to compute an estimate of how much money the subject could expect to earn on net if she accepted the buyout. In addition, the subject received information about the expected effect of her buyout

\footnotetext{
${ }^{6}$ In the experiment, we used the term "buyout" because it is the most straightforward way to explain the option-a monetary payment relieving one of a previous obligation. Despite its many neutral uses (e.g., finance, employment and real estate), some may find it to have negative connotations. We do note that when the underlying context is clear, the use of more neutral wording does not necessarily impact behavior (e.g., Abbink and Hennig-Schmidt (2006) in the context of bribery).
} 
on the number of carbon permits retired. Her screen displayed the exact number of permits that would be purchased with her buyout fee, as well as the number of permits that were retired as a direct result of her performance on the environment tasks in round 1. The difference of these two numbers gave an estimate of the net effect of the buyout on emissions reductions.

After all subjects decided whether or not to accept the buyout option for that round, a subject learned the number of group members accepting the option. ${ }^{7}$ Subjects also learned the expected direct impact of the buyouts on total group contributions. That is, given the realized number of buyout options accepted in the group, we calculated the number of carbon permits purchased with the buyout fees. We then calculated for each buyout subject the number of permits that would have been purchased on behalf of the subject had she not accepted the buyout and, instead, completed the same number of environment tasks as she did in the first environment round. We summed this estimate across all who accepted the buyout, and reported to all group members the difference between this sum and permits purchased with the buyout fees.

\subsection{Treatment Sessions - Unfair Buyout}

At the start of round 3 in the unfair-buyout treatment, we informed all subjects that one half of each group — selected at random — would be offered a buyout option for that round. In round 5 , we informed all subjects that the same subjects would receive the buyout option. They learned that if a subject accepted the buyout, she completed earning tasks and paid a fee equal to one-half her earnings in that round. It was thus common knowledge that all subjects receiving the buyout option would find it profitable to accept. Before choosing, each subject receiving the buyout option was informed of the expected profitability of accepting the offer using the same calculation as in the fair-buyout treatment, and received an estimate of the impact of her buyout on the number of permits retired. As a consequence of the design for the buyout fee in this treatment, these fees were not sufficient to replace effort contributions (unlike the fair buyout), and subjects had sufficient information to infer this. Subjects knew the number of group members offered the buyout and, prior to completing tasks, learned how many group members accepted the buyout.

\subsection{Discussion}

We have taken a number of measures in designing and analyzing the experiment to rule out alternative explanations for a link between effort contributions to the public good and the buyout decisions of others. For example, in some environments, the marginal effect of an individual's effort on the total contribution may depend on the actions of others. Likewise, the level provided by others may affect the marginal benefit of one's contribution (e.g., Bergstrom, Blume and Varian 1986). We address these issues in a number of ways. In terms of marginal productivity of effort, there are no effort or contribution complementarities in producing the group's emission reduction, thus the marginal productivity of a subject's effort in no way depends on peers buying out. In terms of the marginal benefit of reductions, we chose a public good (abatement of carbon emissions) whose

\footnotetext{
${ }^{7}$ Subjects were given no information about the decisions or performance of session participants outside of their own group.
} 
value, given the scale of the problem, is independent of the amount contributed by other subjects. Moreover, even if a subject cares about emissions abated by other subjects (as opposed to worldwide emissions), the implementation of the fair-buyout rule ensured a level of group abatement largely neutral to the number of buyouts accepted. Truthfully revealing to fair-buyout subjects that the buyout itself had a negligible direct effect on contributions helps rule out the possibility that any treatment effects are due to anticipated changes in aggregate contributions as opposed to the act of peers choosing to buy out. Additionally, as noted above, we provided subjects with an estimate of this direct effect. This allows us to control for changes in aggregate contributions by including the expected change in permits as an explanatory variable in our regression analysis.

We also note that observable buyout acceptance provides information about an individual's opportunity cost of effort contributions relative to others. In our fair buyout treatment, a subject for whom buying out is not profitable may correctly infer that she is less adept at the earning task than some of her peers. This is information she would not have received (in our experiment) absent a buyout opportunity. If it is the receipt of this information that causes a reduction in effort and not the buyout per se, this would be a different causal mechanism. To address this possibility, we control for this type of "bad" news in our regression analysis. In addition, we note that subjects in the unfair buyout treatment can make no inferences about the earning-task performance of those accepting the buyout.

Finally, as discussed, the fair-buyout treatment is vulnerable to selection effects. That is, if subjects who choose not to buy out in the fair-buyout treatment sessions differ systematically from the average control subject in environment-task performance, then selection effects could confound our estimates of the treatment effect. We take two basic approaches to addressing this concern. First, the unfair-buyout treatment is not subject to the same criticism because subjects are chosen randomly to receive the buyout offer. Second, in the fair-buyout treatment, we identify subject characteristics which ex post predict buyout acceptance and test whether these characteristics are correlated with environment-task performance in later rounds of the control sessions.

\section{Results}

We start by establishing successful randomization across treatments. In Table 7 of Appendix B, we report by treatment the means and standard deviations for a number of standard demographic variables. We also report $p$-values for tests of differences across control and treatments. We find no significant differences. To summarize, approximately half of subjects were male and half were Caucasian. They were, on average, in the second-year of university studies with approximately two college economics courses, and reported attending religious services less than once per month. Less than one of their peers in the session was someone they considered a friend.

We analyze the results as follows. We begin with our analysis of the fair-buyout treatment. In Section 3.1, we show that the treatment successfully induced buyouts, particularly amongst those who would profit from accepting the offered buyout. We then establish (Section 3.2) our main treatment effect: the introduction of a buyout opportunity reduces effort contributions, par- 
ticularly among those who would have likely lost money by accepting the buyout. In section 3.3, we show that it is peers choosing to buy out (as opposed to the simple introduction of the buyout option) that drives the effect, and show that we do not find support in the data for alternative explanations. Finally, we address the issue of selection. We do not find evidence that high-performing control subjects would have been the most likely to accept the buyout if offered (Section 3.4). We also find a large response to the unfair-buyout treatment, where selection effects are ruled out by random assignment to the buyout option (Section 3.5).

Our key outcome measure is $\delta_{i}$ : for subject $i$, tasks completed for the environment in round 5 minus the number completed in round 1. By focusing on the change in tasks completed, we control for any idiosyncratic differences across treatments in initial task performance. We define this measure for all control-session subjects, and for all treatment-session subjects who do not buyout in round 5. To compare different subject populations, we calculate $\bar{\delta}$, the average $\delta_{i}$ across subjects in the population. Because we cannot reject the hypothesis that the distribution of $\delta_{i}$ is independent of which task was completed for the environment ( $p=0.126)$, we group counting and encryption task observations together.

Finally, while each treatment had two buyout rounds - rounds 3 and 5 - we focus primarily on round 5. When offered for the second time, subjects have had a chance to process the lessons of the first buyout round, and we thus expect a stronger treatment effect in round 5. In fact, the data bear this out. We find no statistically significant effect to either treatment in round 3, but a strong effect in round 5 of both treatments. We discuss in greater detail why round-3 and round-5 behavior might have differed in Section 4.

\subsection{Buyouts in the Fair-Buyout Treatment}

Table 1 describes the pattern of buyouts in rounds 3 and 5 of the fair-buyout treatment. For each 8subject group, the second column identifies the task subjects performed to earn permits. The next two columns indicate the number accepting the buyout in each buyout round. In the final column, we calculate Expected Permit Change for the last buyout round. This is the estimate, provided to subjects, of the direct effect of buyouts for each group: the number of permits purchased with buyout fees minus the number of permits produced in the first environment round by subjects accepting the buyout.

The typical group registered more than one buyout per round with buyouts ranging between zero and four subjects and slightly fewer subjects buying out in round 5 than in round 3 . There is no discernible relationship between the number of buyouts and the environment-round task (encryption or counting). Finally, as the average subject earned approximately one-third of a permit in round 1, the difference between what buyout subjects provided by completing round-1 environment tasks and what their fees purchased is relatively small. In summary, we successfully induced buyouts and variation in buyouts across groups while largely replacing the permits those accepting the buyout might have been expected to provide.

In Figure 1, we use a scatter plot to depict the relationship between round- 5 buyout acceptance 


\begin{tabular}{|c|c|c|c|c|}
\hline \multirow[b]{2}{*}{ Group } & Environment & \multicolumn{2}{|c|}{ Buyouts } & \multirow{2}{*}{$\begin{array}{c}\text { Expected Permit } \\
\text { Change from } \\
\text { Round-5 Buyouts }\end{array}$} \\
\hline & Task & Round 3 & Round 5 & \\
\hline 1 & Encryption & 4 & 3 & 0.13 \\
\hline 2 & Encryption & 2 & 1 & -0.04 \\
\hline 3 & Encryption & 2 & 1 & 0.02 \\
\hline 4 & Encryption & 4 & 3 & -0.05 \\
\hline 5 & Counting & 2 & 0 & 0.00 \\
\hline 6 & Counting & 2 & 2 & -0.13 \\
\hline 7 & Counting & 3 & 3 & 0.10 \\
\hline 8 & Counting & 2 & 1 & -0.08 \\
\hline
\end{tabular}

Table 1: Fair-Buyout Treatment: Number of subjects (out of eight) accepting buyout offer and expected change in permit provision by those accepting buyout, per group.

and task performance. ${ }^{8}$ On the horizontal axis, we have a subject's Earning Task Index: the ratio round- 4 tasks completed by a subject (the last earning round in the experiment) to the median number of tasks completed in that round by members of her group. A subject whose index number is greater than one will profit from accepting the buyout as long as she completes as many earnings tasks in round 5 as she did in round $4 .^{9}$ In what follows, we refer to those subjects for whom this condition is satisfied (not satisfied) as "profitable" ("unprofitable") subjects. On the vertical axis, we have a subject's Environment Task Index: the ratio of the number of tasks a subject completed in round 1 to the median number of tasks completed in that round by members of her group. ${ }^{10}$

We see that buyout acceptance is strongly correlated with its expected profitability. Subjects with an earning-task index above one are much more likely to accept the buyout option, although many rejected a buyout expected to be profitable. In contrast, it is difficult to discern any relationship between environment-task performance and buyout acceptance. In particular, while some may have rejected a profitable buyout because its acceptance would have reduced their public goods contribution, this does not appear to be a general result. Finally, it is worth noting that there is not a strong association between environment and earning task performance in the data.

\subsection{The Effect of Fair-Buyout Treatment on Effort Contributions}

For our first treatment-effect measure, we calculate for each non-buyout subject in round 5 the percent change in tasks completed from round 1 to round $5\left(\delta_{i} /\right.$ Tasks $\left._{1 i}\right)$. In Figure 2, we depict, for the control and each treatment, cumulative distribution functions of this calculation.

We see nearly uniform continued effort contributions in control sessions. In both control and fair-buyout sessions, a significant proportion of subjects complete more tasks in round 5 than

\footnotetext{
${ }^{8}$ Performing the same analysis for round-3 buyout status yields very similar results.

${ }^{9}$ The average Round-5 buyout price was $\$ 4.93$, meaning that the subject who completed $10 \%$ fewer Round- 4 tasks than the median (Earning Task Index $=0.9$ ) would lose approximately $\$ 0.50$ if she accepted the buyout and replicated her Round-4 performance.

${ }^{10}$ The average subject retired .33 permits in the first environment round, meaning that the subject who completed $10 \%$ more Round-1 tasks than the median (Earning-Task Index=1.10) would have reduced her contribution by approximately .03 tons if she accepted the Round -5 buyout instead of replicating her Round-1 environment-task performance.
} 


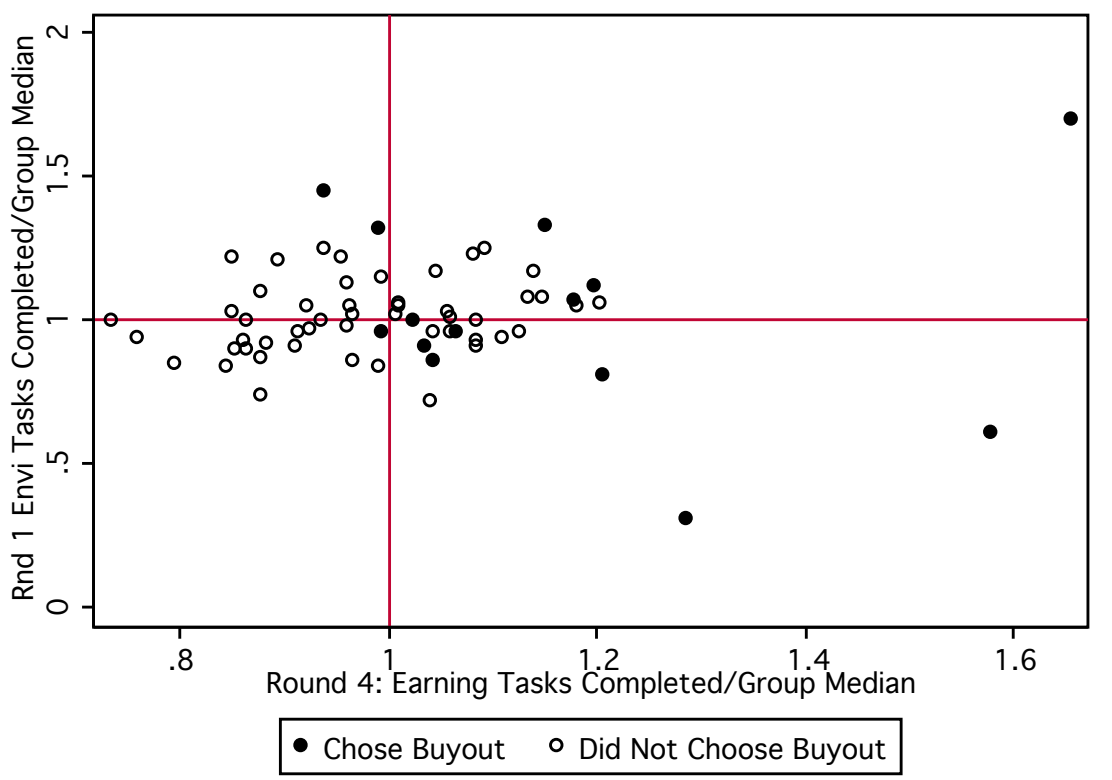

Figure 1: Fair-Buyout Treatment: Relationship between round-5 buyout acceptance in fair-buyout treatment and relative performance on round- 1 environment task and round-4 earnings task.

in round 1, a pattern consistent with the combination of continued effort and learning. ${ }^{11} 33 \%$ of subjects in control sessions and $26 \%$ of non-buyout subjects in fair-buyout sessions increased tasks completed by more than $10 \%$. However, the fraction of subjects completing fewer tasks in round 5 is markedly larger in the fair-buyout treatment than in the control ( $48 \%$ versus $23 \%$ ).

Our next measure is the average change from round 1 to round 5 in environment tasks completed. In Table 2, the rows identify the population: All Subjects; subjects for whom accepting the buyout would have been profitable (Profitable Subjects); and subjects for whom it would not have been (Unprofitable Subjects). The first two columns identify the treatment and control groups, with each cell identifying the average performance change for the subpopulation $(\bar{\delta})$ and number of observations $(n)$. The third column reports the $p$-value of the Wilcoxon rank-sum test of equal distributions. In the final column, we provide a back-of-the-envelope calculation of the economic size of the treatment. For each population, we estimate the change in round- 5 tasks completed if the control group had the treatment's $\bar{\delta}$ instead of its own. ${ }^{12}$

Formal analysis of treatment-wide effects echoes the graphical analysis in Figure 2. Control subjects completed slightly more tasks in round 5 than in round 1, although the difference is not significant. Second, subjects in the fair-buyout treatment who did not accept the buyout completed fewer tasks relative to round 1. The difference between control and fair-buyout subjects not accepting the buyout is statistically significant $(p=0.042)$. We estimate that had we offered the fair buyout to control subjects, subjects not accepting the buyout would have completed $8.8 \%$ fewer

\footnotetext{
${ }^{11}$ For example, we observed subjects experimenting with keyboard and mouse placement.

${ }^{12}$ For each comparison, we take the difference in $\bar{\delta}$, divide by the average number of tasks completed in round 1 of the control sessions, and multiply by 100.
} 


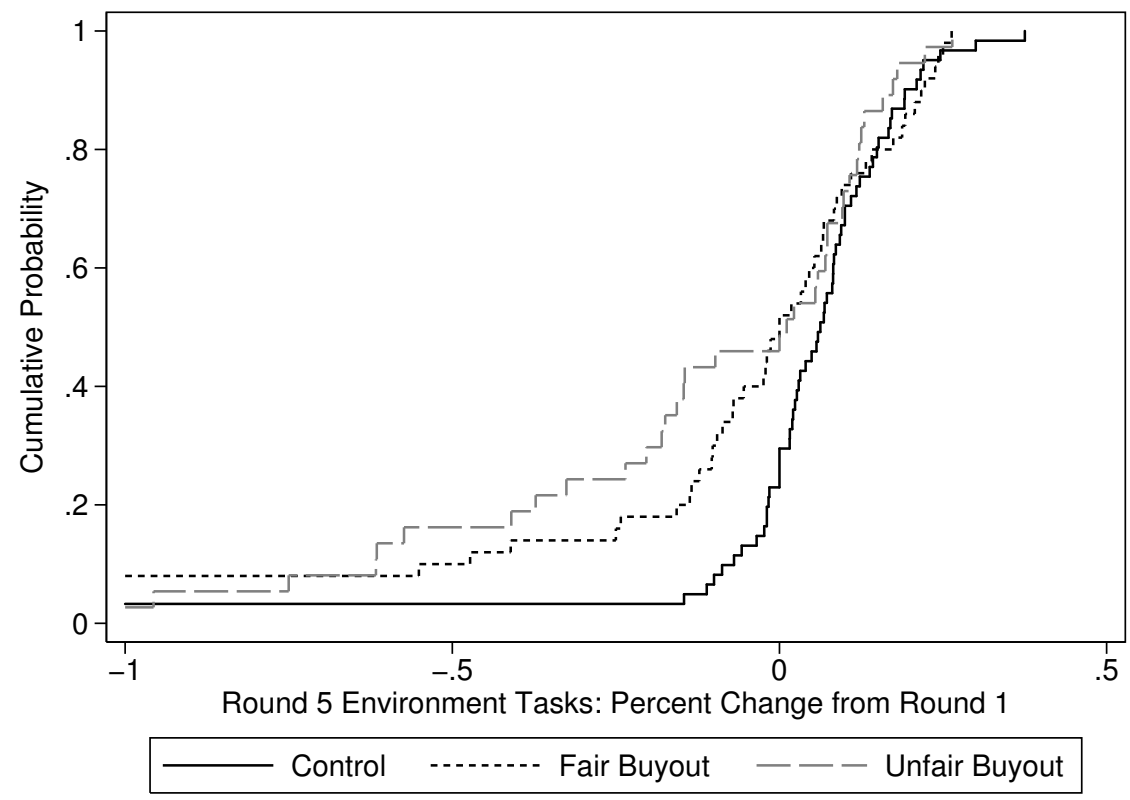

Figure 2: CDFs of percent change in environment tasks completed from round 1 to round 5 for control, fair-buyout and unfair-buyout treatment subjects. (Treatment series exclude subjects accepting round-5 buyout.)

tasks (assuming acceptance uncorrelated with $\delta_{i}$ ). In terms of total permits, including those from buyout fees, whereas the average control group increased permits retired by $2.4 \%$, the average buyout group saw a decrease in total permits of $5.2 \%{ }^{13}$

The treatment averages mask the significant heterogeneity shown in Figure 2. For example, in terms of percent change from round 1, the top third of the control and fair-buyout distributions are nearly indistinguishable. In the bottom two comparisons of Table 2, we distinguish between those who would and would not have expected the buyout to be profitable based on round-4 earning tasks completed. We construct these groups ex post for control subjects using the same rule: a subject completing more round-4 task than her group's median is designated profitable.

On average, unprofitable subjects in the fair-buyout sessions completed fewer tasks in round 5 relative to round 1, whereas the corresponding subjects in control sessions completed approximately the same number of tasks in the two rounds. This difference is both statistically significant and large in an economic sense. We estimate that had we offered the buyout in control sessions, unprofitable subjects would have completed approximately $15.1 \%$ fewer round -5 environment tasks. While the increase in tasks completed is slightly smaller for profitable subjects in fair-buyout sessions than for the corresponding control subjects, we cannot reject the hypothesis that this difference is due to chance. Thus, the aggregate results presented in the first row mask substantial heterogeneity across individuals, as the treatment effect appears to be isolated amongst those for whom the buyout did not make economic sense to accept.

\footnotetext{
${ }^{13}$ We have 8 treatment and 8 control groups. A Monte Carlo permutation test shows that if we randomly select 8 of these 16 observations, only $3.1 \%$ of the time do we get an average reduction of at least $5.2 \%$.
} 


\begin{tabular}{lrrrr}
\hline \hline & \multicolumn{1}{c}{ Fair } & \multicolumn{2}{c}{$\begin{array}{c}\text { Difference as \% of } \\
\text { Round-5 Control }\end{array}$} \\
\hline All Subjects & $\bar{\delta}=1.8$ & $\bar{\delta}=-3.5$ & 0.042 & -8.8 \\
& $n=61$ & $n=50$ & & \\
Unprofitable Subjects & $\bar{\delta}=0.2$ & $\bar{\delta}=-7.9$ & 0.002 & -15.1 \\
& $n=29$ & $n=29$ & & \\
Profitable Subjects & $\bar{\delta}=3.2$ & $\bar{\delta}=2.6$ & 0.387 & -0.9 \\
& $n=32$ & $n=21$ & & \\
\hline \hline
\end{tabular}

Table 2: Fair-Buyout Mean Changes In Environment Tasks Completed by Treatment and Expected Profit: All control subjects and non-buyout subjects in fair-buyout treatment. $p$-values for the Wilcoxon rank-sum test, testing the hypothesis that samples are drawn from the same distribution.

$\delta_{i}=$ Tasks $_{5 i}-$ Tasks $_{1 i}, i \in$ subjects who do not accept buyout. $\bar{\delta}=\sum_{i} \delta_{i} / n$.

\subsection{Decomposing the Causal Mechanism for the Fair-Buyout Treatment Effect}

We now present the results of a regression analysis designed to investigate the cause of our treatment effect. For treatment subjects who likely would not have profited from accepting the buyout, we find a strong negative correlation between the number of peers who buy out and improvements in environment task performance. This is consistent with our preferred explanation that peers choosing to contribute money instead of effort reduces the contributions of those who continue to contribute effort. We do not find support for the competing hypotheses described in 2.4.

In all models, the dependent variable is $\delta_{i}$, the change from round 1 to 5 in tasks completed for the environment. We have one observation from each of the 61 control subjects and the 50 subjects who do not accept the buyout in the fair-buyout treatment. We estimate all models using ordinary least squares (OLS), clustering standard errors at the group level.

One factor that will influence the change in environment tasks completed across rounds is task learning. In fact, a number of subjects completed more tasks in round 5 than in round 1 . All else equal (including effort, ability and tasks completed in round 5) the subject who learned task performance quickly (e.g., in the practice round) will complete more round-1 tasks than the subject who learned more slowly (e.g., in round 3) and will thus have a smaller increase in tasks completed. Therefore, to control for learning independent of any treatment effect, in all specifications we include Round 1 Tasks Completed.

We present our results in Table 3. Our base model (specification (1)) includes controls for the pattern of buyouts and whether the subject would have found the buyout profitable. In the former category, we have Buyout Session, an indicator variable equal to 1 for subjects participating in a buyout session, and Buyout Rate, the fraction of group members accepting the buyout. To capture expected buyout profitability, we include Expected Profitability $>\mathbf{0}$, an indicator variable equal to 1 if the number of tasks completed in the preceding earning round was greater than the group's median and 0 otherwise. ${ }^{14}$ Because this variable is defined for both control and treatment subjects,

\footnotetext{
${ }^{14}$ Estimation results do not qualitatively change when we use continuous measures of expected buyout profitability.
} 


\begin{tabular}{lcccc}
\hline \hline & $(1)$ & $(2)$ & $(3)$ & $(4)$ \\
\hline Round 1 Tasks Completed & 0.0681 & 0.0687 & 0.0439 & 0.0747 \\
& $(0.108)$ & $(0.109)$ & $(0.155)$ & $(0.113)$ \\
Buyout Session & 3.378 & 4.275 & 3.389 & 1.336 \\
& $(5.065)$ & $(4.888)$ & $(5.077)$ & $(7.192)$ \\
Buyout Rate & $-0.551^{* * *}$ & $-0.582^{* * *}$ & $-0.550^{* * *}$ & $-0.593^{* * *}$ \\
& $(0.148)$ & $(0.164)$ & $(0.150)$ & $(0.127)$ \\
Expected Profitability $>\mathbf{0}$ & 2.364 & 2.356 & 2.669 & 2.286 \\
& $(4.255)$ & $(4.278)$ & $(4.610)$ & $(4.296)$ \\
Buyout Session X Expected Profitability $>\mathbf{0}$ & -5.161 & -5.094 & -5.605 & -3.074 \\
& $(7.054)$ & $(7.165)$ & $(7.094)$ & $(9.033)$ \\
Buyout Rate X Expected Profitability $>\mathbf{0}$ & $0.636^{* * *}$ & $0.624^{* * *}$ & $0.643^{* * *}$ & $0.679^{* * *}$ \\
& $(0.169)$ & $(0.174)$ & $(0.166)$ & $(0.171)$ \\
Expected Permit Change & & & & \\
Change Group Permits 1 to 3 & & 19.21 & & \\
Buyout Loss & & $(16.30)$ & & \\
\hline \hline
\end{tabular}

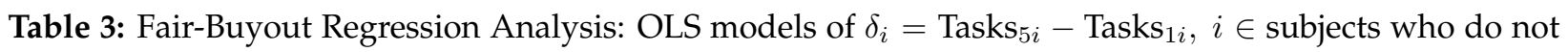
buyout. Standard errors, clustered by group, in parentheses: ${ }^{* * *} p<0.01,{ }^{* *} p<0.05,{ }^{*} p<0.1$.

Independent Variables: Buyout Session $=1$ if buyout offered this session, else 0; Buyout Rate $=$ percentage of group accepting buyout this round; Expected Profitability $>\mathbf{0}=1$ if subject completed more round-4 Earning Tasks than group median, else 0; Expected Permit Change $=$ expected change in the aggregate permits retired this round based on round 1 performance and buyout pattern; Change Group Permits 1 to $3=$ change from round 1 to 3 in permits provided by others in same group; Buyout Loss: If buyout offered and $E[$ Profit $] \leq 0$, then equals $-E[$ Prof], else 0; Interactions indicated with $\mathbf{X}$.

it captures the effect of high earnings independent of any buyout-option effect. We therefore interact Expected Profitability $>0$ with both Buyout Session and Buyout Rate to isolate the effect of the buyout on profitable subjects. With this specification, Buyout Session and Buyout Rate capture the treatment effect on unprofitable subjects.

The coefficients we estimate for our base model suggest that the treatment effect depends on the number of peers accepting the offer. Because we control for the buyout rate, the Buyout Session indicator variable captures the effect of the buyout offer on subjects if no subject in the group 
accepts the buyout. We find no effect here. That is, the coefficient on Buyout Session is very imprecisely estimated and we cannot, therefore, reject the null hypothesis of no association. ${ }^{15}$ We do find a strong effect from the buyout rate. Looking at the subjects who expected the offered buyout to be unprofitable, we estimate an approximately 5.5\% reduction in tasks completed for every 10 percentage-point increase in the percentage of subjects who buy out (assuming a linear response). The equal-in-magnitude but positive coefficient on Buyout Rate $\mathbf{X}$ Expected Profitability $>\mathbf{0}$ is consistent with finding no treatment effect for profitable subjects.

In Specifications (2) - (4), we control for alternative explanations. First, although the fee approximately replaced the effort contributions of those accepting the buyout, it did not do so perfectly. We informed subjects of the difference between the number of permits purchased with buyout fees and the number of permits produced in round 1 by those who bought out in round 5 (Expected Permit Change). We investigate the hypothesis that non-buyout subjects reacted to this by including Expected Permit Change (equal to 0 for control subjects) in specification (2). The data do not support this hypothesis, as we cannot reject the null hypothesis that the coefficient equals zero. Furthermore, including expected permit change does not qualitatively change the coefficients we estimate in specification (1).

Relatedly, while a buyout-treatment subject may focus on the buyout's estimated impact on contributions, a treatment or control subject may condition her round-5 effort contribution on actual round-3 contributions of her peers-a form of conditional cooperation. To investigate this possibility, we calculate for each subject the difference between round-1 and round-3 permits provided by her peers (Change Group Permits 1 to 3), where round-3 permits include those provided by buyout fees. While the average control subject saw total contributions of her peers increase by $1.9 \%$ from round 1 to 3 , the corresponding figure for the average buyout-treatment subject is $2.2 \%$. Model (3) includes this variable. The data do not support the hypothesis that subjects conditioned on round-3 contributions. We cannot reject the hypothesis that the coefficient equals zero, and the variable's inclusion does not qualitatively change the coefficients we estimate in specification (1).

Finally, a fair-buyout subject who cannot afford a buyout accepted by others receives negative information about her relative abilities in the earning task. This information (not available to control subjects in our experiment) did not, however, appear to affect the number of environment tasks completed in the buyout round. First, it might be that learning you cannot afford the buyout while others can may be demotivating. However, we do not estimate a significant coefficient for the variable capturing the fact that a fair-buyout subject's earnings are worse than average (Buyout Session X Expected Profitability $>0$ ) in specifications (1)-(3). Second, it may be that the more unaffordable the buyout, the more demotivating. However, we note that for subjects who cannot afford the buyout, the correlation between the buyout's expected profitability and subsequent-environment task "improvement" is weak (Spearman's $\rho=0.019$ ) and not statistically significant $(p=0.9225)$. Further, we explicitly control for the information conveyed by the buyout's unaffordability in specification (4) by including Buyout Loss which for unprofitable

\footnotetext{
${ }^{15}$ In the one buyout group where nobody accepted the round-5 buyout, only 1 out of 8 subjects completed fewer tasks in round 5 than in round 1 , and this subject's decrease was only $1 \%$ of round- 1 tasks.
} 
buyout-session subjects equals the loss (in dollars) that a she would realize if she had accepted the buyout and completed the same number of earning tasks as she did in the previous round. We set Buyout Loss equal to zero for all other subjects. The inclusion of this variable does not affect our results.

To summarize, we find that the strength of the treatment effect is increasing in the number of peers who accept the buyout offer, consistent with our hypothesis that some reduce their effort contribution to the public good when peers choose to contribute money as opposed to effort. We rule out the possibility that subjects are responding to a perceived change in the level of the public good provided when peers buy out. As well, we do not find support for the idea that unprofitable subjects reduce their effort contributions because they are discouraged when they learn that they are not productive enough take advantage of the buyout option.

\subsection{Are Non-Buyout Subjects Selected on Environment-Task Performance?}

Our fair-buyout results, which we interpret as a treatment effect, rely on comparing those who do not accept the fair buyout with control-session subjects. The latter, however, includes both those who would and would not have accepted the buyout if offered. If those control subjects who would have accepted the buyout are those with larger performance increases (larger $\delta \mathrm{s}$ ), then some of what we attribute to treatment could instead be the result of composition. Before turning to our analysis of the unfair-buyout treatment which eliminates the influence of selection, in this section we provide evidence that composition is not driving our fair-buyout results.

Our strategy is to identify observable factors predicting acceptance of the buyout in the fairbuyout treatment, and show that these factors do not predict performance improvement in controlsession subjects. In addition to buyout profitability, we have identified two relevant demographic characteristics. First, subjects who did not accept an offered round-5 buyout report a higher level of our ordinal measure of Religiosity than subjects in our control group ( $p=0.039$, Table 7 of Appendix B). ${ }^{16}$ Second, gender (captured with the indicator variable Male) is correlated with accepting the round-5 buyout ( $\rho=0.3024, p=0.015$ ). We can find no other characteristic associated with membership in, or selection into, the population rejecting the buyout.

In Table 4, we present regression analysis results. In all models, we include the variables capturing characteristics associated with the buyout group, Male and Religiosity. We include Environment Task Index for two reasons. First, the number of permits an individual might produce if she rejects the buyout may influence her decision. Second, those a with higher round-1 performance (i.e., a higher index) might have learned task performance more quickly and thus might be expected to have a lower $\delta_{i}$. We include either the continuous measure of earning-task performance (Earning Task Index) or the binary measure of expected buyout profitability (Expected Profitability $>0$ ).

In models (1) and (2), we estimate probit models of the round-5 buyout decision using all treatment subjects. The dependent variable, isBuyout, equals one if the subject accepted the round-5

\footnotetext{
${ }^{16}$ While the correlation of self-reported religiosity and rejecting the buyout is not surprising, the results of our exit questionnaire do not give any deeper insight.
} 


\begin{tabular}{lcccc}
\hline \hline & $(1)$ & $(2)$ & $(3)$ & $(4)$ \\
& isBuyout & isBuyout & $\delta_{i}$ & $\delta_{i}$ \\
\hline Environment Task Index & 0.206 & 0.194 & -20.505 & -12.279 \\
& $(0.239)$ & $(0.230)$ & $(15.032)$ & $(11.214)$ \\
Male & $0.196^{*}$ & $0.239^{* *}$ & -3.220 & -2.409 \\
& $(0.113)$ & $(0.097)$ & $(2.452)$ & $(1.718)$ \\
Religiosity & $-0.028^{* *}$ & $-0.031^{* * *}$ & 0.899 & 0.912 \\
& $(0.013)$ & $(0.011)$ & $(0.944)$ & $(0.961)$ \\
Earning Task Index & $1.433^{* * *}$ & & 20.137 & \\
& $(0.438)$ & & $(16.941)$ & \\
Expected Profitability $>\mathbf{0}$ & & $0.239^{* *}$ & & 5.472 \\
& & $(0.095)$ & & $(4.777)$ \\
\hline Observations & 64 & 64 & 61 & 61 \\
\hline \hline
\end{tabular}

Table 4: Probit models of buyout decision in fair-buyout treatment sessions (1-2); OLS models of $\delta_{i}$ in control sessions (3-4). Standard errors, clustered by group, in parentheses: ${ }^{* * *} p<0.01,{ }^{* *} p<0.05$, * $p<0.1$.

Independent Variables: Environment Task Index $=$ round- 1 tasks completed relative to group median; Male $=1$ if male, else 0 ; Religiosity $=$ "How frequently do you attend religious services?" Ordinal with $0=$ Less than once a year, $5=$ More than once a week; Earning Task Index = = round-4 tasks completed relative to group median; Expected Profitability $>0$ $=1$ if round -4 tasks completed $>$ group median, else 0 ;.

buyout and zero otherwise. Whether we use the continuous measure of earning-task performance (Earning Task Index in model (1)) or the indicator for expected buyout profitability (Expected Profitability $>\mathbf{0}$ in model (2)), strong past performance on earning tasks increases the likelihood of buying out. Gender and religiosity are both correlated with buyout acceptance.

In models (3) and (4), we use the same explanatory variables in OLS models of the change in environment-task performance from round 1 to round $5\left(\delta_{i}\right)$ for our 61 control-session subjects. All coefficients are imprecisely estimated. In particular, whereas tasks completed for earning strongly predicts buyout acceptance, neither our continuous measure of earning-task performance (model (3)) nor our binary measure (model (4)) predicts improvement in tasks completed for the environment. In summary, these results do not support the hypothesis that high $\delta$ s are more likely to be found in the cohort that would have accepted the buyout of control sessions.

Finally, we estimated alternative specifications for (1)-(4), including all other demographics variables. As noted above, no other observable characteristic is associated with buyout acceptance. Furthermore, no observable characteristic is correlated with $\delta_{i}$ in control-session subjects.

\subsection{The Effect of the Unfair-Buyout Treatment on Effort Contributions}

This section uses the results of the unfair-buyout treatment to address the issue of selection. The key difference between the fair-buyout and unfair-buyout treatments is that, in the latter, we only offered the option to one half of each treatment group chosen at random, with the same subjects 
offered the option in the two buyout rounds. Thus, an analysis of subjects not offered the buyout will not be affected by selection. We show that while subjects who do not buyout in this treatment register larger environment-task decreases than those in the fair buyout treatment (perhaps due to differences in perceived unfairness), consistent with our main hypothesis we see effort contributions from those not offered the buyout are decreasing in the number of peers who accept.

Table 5 details subject characteristics by buyout status for the unfair-buyout subjects. First, the experiment achieved the desired randomization. Comparing the offered and not-offered groups, there is no significant difference in either environment-task performance ( $p=0.574)$ or earningtask performance ( $p=0.160$ ). Further, amongst those offered the buyout, those accepting the buyout do not significantly differ from those who do not accept it in terms of either environmenttask ( $p=0.795)$ or earning-task $(p=0.150)$ performance. However, compared to those who did not buy out in round 5 , those who bought out in round 5 were more likely to have bought out in round 3 ( $p=0.013)$. We also note that, as in the fair buyout, there is heterogeneity between groups in the number who buyout, with round-5 buyout rates ranging from $12.5 \%$ to $57.1 \% .{ }^{17}$

\begin{tabular}{rrrrr}
\hline \hline $\begin{array}{r}\text { Buyout Accepted: } \\
\text { Buyout Offered: }\end{array}$ & No & Yes & $\begin{array}{r}\text { No } \\
\text { Yes }\end{array}$ & $\begin{array}{r}\text { Yes } \\
\text { Yes }\end{array}$ \\
\hline Environment Task Index & 1.045 & 1.042 & 1.036 & 1.043 \\
& $(0.236)$ & $(0.164)$ & $(0.162)$ & $(0.168)$ \\
Earning Task Index & 1.034 & 0.962 & 1.050 & 0.937 \\
& $(0.170)$ & $(0.168)$ & $(0.154)$ & $(0.167)$ \\
Buyout in Round 3 & 0.000 & 0.677 & 0.286 & 0.792 \\
& $(0.000)$ & $(0.475)$ & $(0.488)$ & $(0.415)$ \\
& & & & \\
$n$ & 30 & 31 & 7 & 24 \\
\hline \hline
\end{tabular}

Table 5: Unfair Buyout Treatment: Subject characteristics (means and standard deviations) by round-5 buyout status.

In measuring the treatment effect, we first look at all subjects. We first refer back to Figure 2 where we depict, by treatment, cumulative distribution functions of the percent change in tasks completed (round 5 relative to round 1) by non-buyout subjects. As in the control and fair-buyout sessions, we see a significant portion of subjects in the unfair buyout completing more tasks in round 5 than in round 1 , with $27 \%$ increasing by at least $10 \%$. However, we see an even more pronounced treatment effect, with over $43 \%$ of non-buyout subjects registering decreases in tasks completed of at least $10 \%$.

Formal tests of the differences between the control and the unfair buyout yield results similar to the comparison of the control and fair buyout. For non-buyout subjects in the unfair-buyout treatment, the average change in tasks completed for the environment from round 1 to 5 was $\bar{\delta}=$ -7.1 . This is statistically different than $\bar{\delta}=1.8$ in the control ( $p=0.028)$. Our main comparisonbetween control subjects and those not offered the unfair buyout-rules out selection. Whereas the subjects not accepting the unfair buyout completed 6.1 more tasks on average, subjects not

\footnotetext{
${ }^{17}$ Four subjects bought out in a group of 7 which explains why the range of buyout rates exceeds $50 \%$.
} 
offered the unfair buyout completed 10.2 fewer tasks on average, again significantly less than the control $(p=0.008)$.

\begin{tabular}{lcc}
\hline \hline & $(1)$ & $(2)$ \\
\hline Round 1 Tasks Completed & 0.0599 & 0.120 \\
& $(0.0768)$ & $(0.0943)$ \\
Buyout Not Offered & $-11.95^{* * *}$ & 8.063 \\
& $(3.502)$ & $(4.875)$ \\
Buyout Not Accepted & $4.548^{* * *}$ & $7.136^{* * *}$ \\
& $(1.493)$ & $(1.635)$ \\
Not Offered X Buyout Rate & & $-0.511^{* * *}$ \\
& & $(0.116)$ \\
Not Accepted X Buyout Rate & & -0.105 \\
& & $(0.0613)$ \\
Constant & & \\
& -1.829 & -5.396 \\
Observations & $(4.876)$ & $(5.942)$ \\
\hline \hline
\end{tabular}

Table 6: Unfair-Buyout Regression Analysis: OLS models of $\delta_{i}=$ Tasks $_{5 i}-$ Tasks $_{1 i}, i \in$ subjects who do not buyout in control and unfair buyout. Standard errors, clustered by group, in parentheses: ${ }^{* *} p<0.01$, ${ }^{* *} p<0.05,{ }^{*} p<0.1$.

Independent Variables: Buyout Not Offered $=1$ if unfair-buyout subject not offered buyout, else 0; Buyout Not Accepted $=1$ if subject did not accept offered buyout, else 0 ; Interactions indicated with $\mathbf{X}$.

In Table 6, we present estimates of OLS models of $\delta_{i}$ with errors clustered at the group level. In both specifications, we have one observation from each of the 61 control subjects and the 37 subjects who either were not offered or did not accept the unfair buyout. In model (1), in addition to Round 1 Tasks Completed, we include only indicator variables capturing whether an unfair-buyout subject was not offered the buyout or chose not to accept the buyout. We estimate that - compared to control subjects - those not offered the buyout significantly decrease tasks completed, whereas those who complete round- 5 environment tasks because they turned down the offer complete more tasks. In the second model, we interact these indicator variables with the buyout rate. The estimates suggest that while the increase in tasks completed by those who decline the buyout is independent of the number who accept the offer, the decrease amongst those not receiving the offer comes not from the introduction of the buyout itself, but rather from the fraction accepting the offer. This is consistent our findings from the fair-buyout treatment.

Overall, we find that the reduction in tasks completed by non-buyout subjects in this treatment is at least as large as the reduction by non-buyout subjects in the fair-buyout treatment, despite the fact that those who reject the unfair buyout register larger increases than the average control subject. We speculate that perceived differences in fairness of the buyout rules may play a role in the particularly large decrease from those not offered the buyout. However, restricting the com- 
parison to only those subjects not offered the buyout gives results consistent with the fair-buyout results in that the output reductions arise from the number accepting the buyout. Therefore, in a comparison immune to selection effects, we find further support for the hypothesis that peers choosing to contribute money in lieu of effort results in reduced contributions from those who must continue to make effort contributions.

\section{CONCLUSION AND Discussion}

If the fact that Mr. Gore chooses to avail himself of market-based solutions to environmental problems results only in hurt feelings, then perhaps there is little to worry about. If these choices result in measurable changes in aggregate contributions to public goods, then they have the potential to alter the effectiveness of policy interventions.

We designed an experiment to test the hypothesis that allowing some to contribute money instead of effort to the public good results in reduced effort contributions by those who continue to contribute effort. We find substantially decreased effort contributions in the second buyout round relative to the corresponding control round. We also observe heterogenous effects. First, while those who decline the buyout despite its profitability do not decrease effort contributions, many of those who cannot buyout - either because the buyout is unavailable or unprofitablerespond by completing fewer tasks, consistent with a reduction in effort. Second, the decreased effort contribution depends on the number of group members accepting the offer.

These patterns support our preferred explanation that when peers contribute money, it makes subjects who are, in some sense, "forced" to continue contributing effort less willing to do so. In this way, our results are consistent with findings of conditional cooperation in public goods environments. For those accepting the buyout, contributing money in lieu of effort was less costly, and plausibly those who responded with decreased effort contributions viewed less costly contributions as lesser contributions.

Broadly, we see two implications. First, our setting elicited high levels of voluntary effort contributions throughout the rounds of control sessions. That is, we find a high level of round-1 contributions ${ }^{18}$ with very little decay across environment rounds. Thus, the treatment appears to have damaged an otherwise healthy institution. The provision of many local public goods rely on similar institutions and, therefore, could be susceptible to our treatment effect. As a result, our experiment may help explain why many groups and organizations (including the running club to which one of the authors belongs) do not allow members to replace effort obligations with cash contributions. While the buyout's efficiency gains may be tempting, perhaps experience has shown that they are not worth cost of the offsetting effort reductions.

Second, our study is, to the best of our knowledge, the first empirical support for the hypothesized link between willingness to exert effort for the public good and the contribution vehicle of others. While our results do not argue against market-based solutions in general (and especially

\footnotetext{
${ }^{18}$ For each task we cannot reject the hypothesis that tasks completed in round- 1 when it is the environment task is the same as it is in round 2 when it is the earnings task: $p=0.452$ for counting and $p=0.093$ for encryption.
} 
not when voluntary effort contributions will assuredly result in inefficiently low levels of contribution), the effects in this experiment are large. Both the pattern of our results and the environment in which they occurred point to aspects for policy makers and future researchers to consider.

Notably, in both treatments, the large negative effects only occurred the second time we offered the buyout. Importantly, those subjects who decreased output in round 5 mostly did not buyout in round 3. ${ }^{19}$ This means that those who decreased output in round 5 had the opportunity to do so in round 3, but chose not to. Based on this, two hypotheses as to why the treatment effect might be stronger in round 5 present themselves. First, consistent with other studies (e.g., Cooper and Stockman 2002), it might simply be that it takes time for subjects to realize how they feel about the institution. Alternatively, it might be that in round 3, subjects are unsure about what the future holds. For example, a subject unable to buyout in round 3 might have believed it a one-time occurrence or that future buyouts would be profitable. When, in round 5 , she sees that the buyout option is a durable and unprofitable feature of the experiment, she may have plausibly reacted more strongly. These are not testable hypotheses within our experiment design, but they could profitably be taken up in future research.

Our experiment environment captures many of the salient aspects of buyout options. Most notably, we implemented an environment where individuals differ in the opportunity cost of their time and must choose whether or not to accept an opportunity to contribute money instead of effort. Of course, there will be significant variability in non-laboratory buyout environments, and we were thus forced to make a number of design choices. We consider how some of these differences between our environment and particular buyout opportunities might affect outcomes.

First, subjects likely felt little group identity and were not selected into the group based on intrinsic concern for the public good. It is unclear whether changing these aspects would strengthen or weaken the effects found in the laboratory. For example, while increased group identity (or commitment to the public good) might increase the sting of others replacing effort with money, increased weight on the group's welfare might steel resolve despite this sting. ${ }^{20}$

Characteristics of the public-good effort task may well affect willingness to reduce effort contributions when others replace effort with money. Our laboratory tasks were solitary and separable (i.e., there was neither group-member interaction nor effort complementarities). Furthermore, subjects reported little intrinsic motivation to complete the tasks, and performance - both in terms of number of tasks and ultimate emission reduction - was measurable. Differences in any of these dimensions will plausibly affect willingness to contribute to the public good in effort while others contribute otherwise.

In some environments, an individual's effort contribution to the public good will be public. People may use public participation and effort choice to signal attributes such as caring for the environment (Bénabou and Tirole 2006). This signal may be more clear from a person who has

\footnotetext{
${ }^{19}$ Consider subjects who completed fewer tasks in round 5 than in round 1 . In the fair-buyout treatment, 19 of the 24 such subjects did not buyout in round 3. In the unfair-treatment, all 17 such subjects were not able to buyout.

${ }^{20}$ In fact, Chen and Li (2009) find experimental evidence that subjects are less likely to punish in-group members for misbehavior.
} 
publicly passed up an opportunity to buyout of the prosocial effort, which may mitigate the strong effect we find in the laboratory.

The fact that total contributions (including buyout fees) decreased from round 1 to 5 in the fair-buyout treatment (compared to increasing in the control treatment) is partly due to limited potential efficiency gains in our experiment. In other environments, potential efficiency gains may be much more substantial. For example, an hour of lawyering can pay for a lot of burger flipping at the fundraiser. When opportunity costs vary widely, requiring those who buyout to replace more than their effort might both offset and reduce the behavioural response of those who do not buyout.

Relatedly, selection is integral to market mechanisms and will affect overall outcomes. In our experiment, selection did not play a large role largely because there was no clear correlation in performance across the tasks. In cases where the opportunity cost of effort and productivity in public-good production are positively correlated, allowing those with the highest opportunity cost to buy out will compound, and may plausibly exacerbate, the behavioral response we identified.

A final aspect of our experiment that deserves further consideration is the fact that those accepting the buyout were able to earn money as the alternative activity. One possibility is that to the extent that market-based mechanisms highlight or exacerbate pre-existing inequality — an aversion to income inequality might underlie objections to their use. The notion that people care about their relative consumption in addition to their absolute level of consumption has a long history in economics (Duesenberry 1949), and the public policy implications of this hypothesis have been well studied (e.g., Boskin and Sheshinski 1978, Layard 1980, Persson 1995, Carroll, Overland and Weil 1997). Thus, due to the increased earning inequality introduced by the buyout in our experiment, we cannot rule out the possibility that inequality aversion contributed to our treatment effect. ${ }^{21}$ We note, however, the while concern for inequality is plausible as a reason to oppose the use of markets, why it should be linked to the crowding effect we observe is far less clear, as reduced effort does nothing to reduce inequality. Furthermore, there is evidence suggesting that wealth and income inequality need not adversely affect voluntary contributions to public goods (Buckley and Croson 2006).

A second possibility is that earning money in lieu of contributing effort to the public good might have a more direct effect: it may simply be aggravating to non-buyout subjects that some are earning money while others are expected to contribute their labors to the public good. In other contexts, someone accepting a buyout may be doing something "better" with his time, such as caring for a family member, which may mitigate the perceived injustice.

\footnotetext{
${ }^{21}$ While we did not share the earnings of those who did buyout, it is clear in the unfair buyout that subjects buying out made money. In the fair buyout, it would be reasonable for subjects to infer both that the higher earners were more likely to buyout and these already high earners would be making more money.
} 


\section{REFERENCES}

Abbink, Klaus and Heike Hennig-Schmidt, "Neutral versus loaded instructions in a bribery experiment," Experimental Economics, June 2006, 9 (2), 103-121.

Alexander, Keith L., "Outsourcing the Picket Line," The Washington Post, July 24, 2007.

Bénabou, Roland and Jean Tirole, "Incentives and Prosocial Behavior," American Economic Review, December 2006, 96 (5), 1652-1678.

Bergstrom, Theodore, Lawrance Blume, and Hal Varian, "On the Private Provision of Public Goods," Journal of Public Economics, 1986, 29 (1), 25-49.

Boskin, Michael J. and Eytan Sheshinski, “Optimal Redistributive Taxation When Individual Welfare Depends upon Relative Income," Quarterly Journal of Economics, November 1978, 92 (4), 589-601.

Brüggen, Alexander and Martin Strobel, "Real effort versus chosen effort in experiments," Economics Letters, 2007, 96 (2), 232-236.

Buckley, Edward and Rachel Croson, "Income and wealth heterogeneity in the voluntary provision of linear public goods," Journal of Public Economics, May 2006, 90 (4-5), 935-955.

Carroll, Christopher D., Jody Overland, and David N. Weil, "Comparison Utility in a Growth Model," Journal of Economic Growth, December 1997, 2 (4), 339-367. 10.1023/ A:1009740920294.

Chen, Yan and Sherry Xin Li, "Group Identity and Social Preferences," American Economic Review, March 2009, 99 (1), 431-457.

Cooper, David J. and Carol Kraker Stockman, "Fairness and Learning: An Experimental Examination," Games and Economic Behavior, October 2002, 41 (1), 26-45.

Duesenberry, James Stemble, Income, Saving and the Theory of Consumer Behaviour, Cambridge, MA: Harvard University Press, 1949.

Ellingsen, Tore and Magnus Johannesson, "Time is not money," Journal of Economic Behavior E Organization, October 2009, 72 (1), 96-102.

Fischbacher, Urs, “z-Tree: Zurich Toolbox for Ready-made Economic Experiments," Experimental Economics, June 2007, 10 (2), 171-178.

Frey, Bruno S. and Reto Jegen, "Motivation Crowding Theory: A Survey of Empirical Evidence," Journal of Economic Surveys, December 2001, 15 (5), 589-611.

Gächter, Simon, "Conditional Cooperation: Behavioral Regularities from the Lab and the Field and Their Policy Implications," in Bruno S. Frey and Alois Stutzer, eds., Economics and Psychology: A Promising New Cross-Disciplinary Field, CESifo Seminar Series, Cambridge, MA: MIT Press, 2007, chapter 2, pp. 19-50. 
Gneezy, Uri and Aldo Rustichini, "A Fine Is a Price," Journal of Legal Studies, January 2000, 29 (1), $1-17$.

Greiner, Ben, "An Online Recruitment System for Economic Experiments," in Kurt Kremer and Volker Macho, eds., Forschung und wissenschaftliches Rechnen 2003, Vol. 63 of GWDGBericht, Göttingen, Germany: Gesellschaft für wissenschaftliche Datenverarbeitung mbh, 2004, pp. 79-93.

Heal, Geoffrey, "A Celebration of Environmental and Resource Economics," Review of Environmental Economics and Policy, Winter 2007, 1 (1), 7-25.

Humphrey, Mark, “Group says Gore’s home overuses electricity,” USA Today, February 27, 2007.

Layard, R., "Human Satisfactions and Public Policy," The Economic Journal, 1980, 90 (360), 737-750.

Persson, Mats, "Why Are Taxes So High in Egalitarian Societies?," The Scandinavian Journal of Economics, 1995, 97 (4), 569-580.

Rousseau, Jean-Jacques, The Social Contract 1762.

Sandel, Michael J., What Money Can't Buy, Farrar, Straus and Giroux, 2012.

Vilares, Iris, Gregory Dam, and Konrad Kording, "Trust and Reciprocity: Are Effort and Money Equivalent?," PLoS ONE, 02 2011, 6 (2), e17113. 


\section{A SESSION INSTRUCTIONS}

\section{Introduction}

- You are about to participate in a session in which you will complete tasks at a computer. This is part of a study intended to provide insight into certain features of decision processes. I encourage you to follow the instructions carefully. You will be paid in cash at the end of the session.

- During the session, I ask that you please do not talk to or otherwise communicate with (e.g., text messaging) each other. If you have a question, please raise your hand and a session moderator will assist you.

- In consideration for others in the session, we do ask that you take a moment to make sure that the ringer on your cell phone is off.

- Your computer screen should have two open windows: an internet browser and a "Welcome to z-Leaf" window. If these two windows are not open on your screen, please raise your hand.

- During the session, you are free to use the internet browser on your computer. The session monitor will inform you when you are required to respond to the $\mathrm{z}$-Leaf window.

- You should have a pen and two blank sheets of paper at your workspace. Please check to make sure the pen works. If you do not have these items, or if your pen does not work, please raise your hand.

- During this session, you are going to be assigned to a group. In some parts of this experiment, you and your group members will have the opportunity to complete computer-based tasks for the environment, where more tasks completed will lead to larger reductions in greenhouse-gas emissions, believed by most scientists to be a leading contributor to global warming. Before continuing with the more detailed session instructions, we would like to give you an idea of how this will work.

- According to the Intergovernmental Panel on Climate Change: Global atmospheric concentrations of greenhouse gas emissions have increased markedly as a result of human activities. Scientists have very high confidence that this process has caused increases in global average air and ocean temperatures, widespread melting of snow and ice, and rising sea levels. The likely range for warming by the end of the 21st century is between 5 and 14 degrees F. The effects will last for centuries due to the long-lived nature of emissions. The longerterm magnitude of these effects and the impacts on different regions of the planet are less certain but will likely include widespread changes in precipitation amounts, ocean salinity, wind patterns and aspects of extreme weather including droughts, heavy precipitation, heat waves and the intensity of tropical cyclones. While some changes might be beneficial (like 
longer growing seasons for agriculture), on balance scientists believe these changes will be damaging to humans. There is also some small risk that there could be catastrophic impacts, such as major reductions in polar ice that could result in approximately 15-20 feet of sea level rise.

- The tasks you and your group complete in the Environment Rounds directly reduce greenhouse gas emissions. The European Union Emission Trading System, which came into effect in 2005, caps the number of tons of greenhouse gas emissions EU member countries may produce in any year. In order to emit greenhouse gases, a polluter needs a permit, with the total number of permits equal to the total number of tons allowed. Based on the number of tasks you and your group complete in Environment rounds, session sponsors will purchase the appropriate number permits. We will retire these permits. That is, we will not sell these permits to emit greenhouse gases, and thus the number of tons of greenhouse gases emitted will decrease by this amount. Therefore, your effort in Environment rounds directly reduces greenhouse gas emissions.

- Driving a mid-size car from Palm Beach, FL to Williamstown, MA produces the equivalent of approximately .7 tons of carbon dioxide, a greenhouse gas.

\section{Procedures}

- At the start of the session, the computer randomly assigns one-half of participants to the Blue group and one-half to the Purple group. You remain in the same group for the entire session.

- This session will proceed in a series of 5-minute rounds.

- In Environment Rounds, you are presented with counting tasks in your z-Leaf window. At the end of the round, the computer adds up the number of tasks completed by members of your group. For each 200 counting tasks, the session sponsors will purchase and retire a permit to emit one ton of carbon dioxide, directly reducing global greenhouse-gas emissions by that amount. (If the total is not divisible by 200, the appropriate fraction of a permit will be purchased.)

- In Earning Rounds, you are presented with encryption tasks in your z-Leaf window. At the end of the session, you receive a cash payment of $\$ 0.10$ (10 cents) for each encryption task you complete.

- The Encryption Task: In your z-Leaf window, there will be a table translating each letter of the alphabet into a unique 2-digit number. This table remains the same for the round. For each task, your monitor presents you with 2 letters. You complete a task by translating the 2 letters into their numeric equivalent, entering the correct 4 numbers (without spaces) into a box on your monitor, and clicking the OK button. Once you have entered the correct 4 numbers, your monitor presents you with the next 2 letters. 
- The Counting Task: For each task, your z-Leaf window presents you with a table with 4 rows and 4 columns with either a 0 or 1 in each position. You complete a task by counting the number of zeros, entering the correct number into a box on your monitor, and clicking the OK button. Once you have entered the correct number of zeros, your z-Leaf window presents you with the next table.

- At the start of each round, your z-Leaf window will inform you whether the round is an Environment Round or an Earning Round.

- At the end of each Earning Round, your z-Leaf window will display the number of encryption tasks you completed and the amount of money you earned.

- At the end of each Environment Round, your z-Leaf window will display the number of counting tasks completed by you and your group as a whole. It will also display the number of tons greenhouse gas emissions your group has prevented.

- The experiment will start with two one-minute practice rounds (one encryption and one counting). The purpose of the practice rounds is to give you an opportunity to familiarize yourself with the computer interface. You will not earn money in the practice rounds, nor will greenhouse gas permits be purchased.

- At the end of the experiment, I will pay you, in cash, your participation fee plus your earnings from all Earning Rounds. I will also provide you with a web address where you may verify the purchase of greenhouse gas permits that your group earned. At the end of the calendar year, you may verify that all of the permits have been retired (that is, none have been resold).

- Are there any questions?

\section{A.1 Buyout Instructions}

\section{You and everyone in your Group will be offered a Buyout Option this round. Please read carefully.}

- If you accept the Buyout Option, you pay a Buyout Fee: a flat fee which session sponsors will use to purchase and retire as many greenhouse gas permits as possible.

- If you accept the Buyout Option, your computer will present you with earning (encryption) tasks. The amount you would receive per completed encryption task may be different than in regular Earning Rounds. If you accept the Buyout Option, your earnings, which may be negative, would be the number of encryption tasks you complete times the amount per completed encryption task, minus the Buyout Fee.

- All members of your group are offered the same Buyout Fee, which you would pay only if you accept the Buyout Option. Also,all members of your group will be offered the same number of cents per completed encryption task. 
- The Buyout Fee has been calculated to replace the average number of permits produced in the first Environment Round. Thus, if your 8 group members retired a total of 8 pollution permits in the first Environment Round, the calculated Buyout Fee will be exactly equal to the price of 1 pollution permit.

- If you do not accept the Buyout option, your Environment Round proceeds as usual. Your computer presents you with counting tasks, with the session sponsor purchasing and retiring 1 ton of greenhouse gas emissions for each 200 tasks.

- At the end of the round, the computer adds up:

1. all Environments tasks completed by group members not accepting the Buyout option, with the session sponsor purchasing and retiring a permit for 1 ton of greenhouse gas emissions for each 200 successfully completed Environment tasks; and

2. the Buyout Fees collected from group members accepting the Buyout Option, with the session sponsor using these fees to retire as many greenhouse gas permits as possible.

- On the next screen, your monitor will display information which may be helpful in deciding whether to accept the Buyout Option:

- the Buyout Fee;

- the amount you will receive per encryption task if you accept the Buyout option;

- your earnings if you complete as many encryption tasks as last round;

- the number of greenhouse gas permits retired if you pay the Buyout Fee; and

- the number of greenhouse gas permits retired as a result of the number of counting tasks you personally completed in the first Environment Round.

- Are there any questions? 


\section{B AdDitional Results}

\begin{tabular}{|c|c|c|c|c|c|c|}
\hline & Control & $\begin{array}{r}\text { Fair } \\
\text { Buyout }\end{array}$ & $\begin{array}{l}\text { Unfair } \\
\text { Buyout }\end{array}$ & $\begin{array}{l}\text { Fair Buyout } \\
\text { Buyout=No }\end{array}$ & \multicolumn{2}{|c|}{$p$-value } \\
\hline & (1) & $(2)$ & (3) & $(4)$ & $(1)=(2)=(3) ?$ & $(1)=(4) ?$ \\
\hline \multirow[t]{2}{*}{ Male } & 0.541 & 0.541 & 0.500 & 0.420 & 0.868 & 0.205 \\
\hline & $(0.502)$ & $(0.502)$ & $(0.504)$ & $(0.499)$ & & \\
\hline \multirow[t]{2}{*}{ Caucasian } & 0.508 & 0.574 & 0.562 & 0.560 & 0.738 & 0.586 \\
\hline & $(0.504)$ & $(0.499)$ & $(0.500)$ & $(0.501)$ & & \\
\hline \multirow[t]{2}{*}{ School Year } & 2.131 & 2.279 & 2.516 & 2.480 & 0.176 & 0.119 \\
\hline & $(1.176)$ & $(1.082)$ & $(1.221)$ & $(1.233)$ & & \\
\hline \multirow[t]{2}{*}{ Number Econ Courses } & 2.083 & 2.155 & 2.172 & 1.900 & 0.467 & 0.194 \\
\hline & $(2.854)$ & $(2.581)$ & (3.293) & $(2.957)$ & & \\
\hline \multirow[t]{2}{*}{ Religiosity } & 0.885 & 1.086 & 1.203 & 1.280 & 0.132 & 0.039 \\
\hline & $(1.439)$ & $(1.430)$ & $(1.371)$ & $(1.485)$ & & \\
\hline \multirow[t]{2}{*}{ Number Friends in Session } & 0.881 & 0.741 & 0.609 & 0.600 & 0.345 & 0.129 \\
\hline & (1.161) & (1.069) & (1.149) & (1.245) & & \\
\hline Observations & 61 & 61 & 64 & 50 & & \\
\hline
\end{tabular}

Table 7: Summary Statistics for Subject Demographic Characteristics Male $=$ binary indicator is 1 if subject is male, else 0; Caucasian $=$ binary indicator is 1 if subject is Caucasian, else 0; School Year = ordinal years of college completed; Number Econ Courses $=$ ordinal number of college economics courses completed; Religiosity = "How frequently do you attend religious services?" Ordinal with $0=$ Less than once a year, $5=$ More than once a week. Number Friends in Session $=$ ordinal number of friends in session. Statistical tests for Male and Caucasian (binary variables) use Chi-Square. Other comparisons (i.e., ordinal) use Kruskal Wallis. 